Martin Shubik*

\title{
Accounting and its Relationship to General Equilibrium Theory
}

https://doi.org/10.1515/ael-2018-0054

\begin{abstract}
Accounting both for macro and microeconomic purposes deals with process and dynamics. Much of the best microeconomic theory has dealt only with statics. General equilibrium theory shows the virtues of a price system, but abstracts from price formation and all of the accounting problems which appear in disequilibrium. An approach is suggested here for reconciliation of accounting with general equilibrium. More generally, it is suggested that the importance of accounting to economic theory has been underestimated.
\end{abstract}

Keywords: macroeconomics, microeconomics, general equilibrium

\section{Tribute to Martin Shubik}

1. “Accounting and its Relationship to General Equilibrium Theory” by Martin Shubik, https:// doi.org/10.1515/ael-2018-0054

2. “Martin Shubik's Curriculum Vitae” by Shyam Sunder, https://doi.org/10.1515/ael-2019-2047

3. "The Visible Hand" by Andrew W. Lo, https://doi.org/10.1515/ael-2018-0012

4. "What Makes Money Work? Comments on "The Guidance of an Enterprise Economy"” by Joel Sobel, https://doi.org/10.1515/ael-2017-0051

5. "Institutions, Games and Economic Theory: Comments on the Guidance of an Enterprise Economy by Martin Shubik and Eric Smith, MIT Press 2016" by Douglas W. Diamond, https://doi.org/10.1515/ael-2019-0047

6. "Equilibrium and System Analysis in Economic Dynamics. A Comment on the "Guidance of an Enterprise economy" by Martin Shubik and Eric Smith" by Yuri Biondi, https://doi.org/ 10.1515/ael-2018-0027

The history of the development of the concepts of national income has been given by Studenski (1958) where he attributes its origin in the seventeenth century to Sir William Petty in England and Pierre le Pesant Sieur de Boisguillebert in France. He notes various theories of economic production and hence several variants of what has been called national income. In particular to this day three have survived. They are: the comprehensive production concept which counts goods and services; the restricted material concept which counts only material goods and the restricted market production concept which includes only goods and services

*Corresponding author: Martin Shubik, Yale University, Department of Economics, New Haven, CT USA, E-mail: martin.shubik@yale.edu 
which have been delivered through the markets. Studenski suggests that Adam Smith's emphasis on the restricted material product concept may have set back the development of economics for some time.

Without delving further into the history of national income accounting it is reasonably safe to argue that by the end of World War II virtually all economists agreed upon the comprehensive production view of national income. But to this day many problems still exist in the measurement of non-market production and the gaps abound among macro-economic accounting conventions, microeconomic accounting and microeconomic theory definitions.

Far earlier than the needs of government called for the development of macroeconomic accounting, the needs of trade and production called for accounting for business. By the fifteenth century a comprehensive and logically ordered system of record keeping had become a necessity if businesses were going to grow in size and trade were to continue to expand. In 1494 the great work of Fra' Luca Pacioli (1494) laid out the basic principles of double entry bookkeeping and provided the basis for the development of modem business accounting.

Both of the developments in accounting, even when regarded at the highest levels of abstraction were and are of this world. They were directed towards helping governments and firms to cope with ongoing problems of day to day and year to year decision-making. First and foremost, accounting of all varieties has had to grapple with the dynamics of both the firm and government. A balance sheet may present a moment frozen in time, but the income statements linking two balance sheets deal directly with the dynamics of an ongoing system.

The development of macro and microeconomic theory took different routes. Macro-economic analysis, even though partially captured by the mathematical methodology that has invaded virtually all aspects of economics, nevertheless has maintained a high content of institutional structure and a basic concern for dynamics. The causality implicit in the macroeconomic models and the predictions based upon them depend directly on a host of macroeconomic accounting assumptions. These deal with how household production is evaluated; what constitutes savings; how capital stock is evaluated; how depreciation is measured; what constitutes unemployment; how is inflation measured and many other factors usually involving both deep conceptual problems in the treatment of time and uncertainty. They also deal with fundamental economic and mathematical problems in obtaining optimal scalar or one number representations of phenomena which at best are multidimensional, or do not even have good numerical representation. An example of the measurement difficulties is provided when one tries to correct the growth of productivity for changes in the variety, quality and mixture of goods produced. If the conceptual problems, 
however deep were merely confined to the academies they would not matter very much. They would increase employment for university professors and make little difference to the functioning of society as a whole. Unfortunately a cast of living index, or an inflation index or a measurement of the level of unemployment may be used to influence vital political decisions. Academic economists are also citizens and as such they cannot avoid the responsibilities which must be assumed when one index is selected over another.

Many of the basic problems with the national income accounts have been covered in the paper in this journal by Richard Ruggles, ${ }^{1}$ the emphasis here is in on microeconomics. Microeconomic theory since the 1930s has developed in a considerably different manner from macroeconomics. The domain of study of microeconomics is vast and is split into many sub-disciplines. The theory of the firm, consumer choice, oligopoly theory and industrial organization maintained a high empirical content until the recent invasion of game theory, the central development in the study of the basic logic of markets, production and trade took a different turn. As the fascination with the understanding of the price system grew, progressively higher and higher levels of abstraction were considered until with the publication of Gerard Debreu's Theory of Value (1959) an elegant mathematical treatise presented the basic features of an efficient production and distribution of resources governed by individual optimization given the signal of an appropriate price system. The mathematics showed the conditions required for existence of such a price system but provided no indication as to how the prices were to be attained. Furthermore it was shown that in general the prices which would clear all markets efficiently were not necessarily unique. The few verbal commentaries in the book intimated that the mathematics represented the appropriate formulation of the concepts of a competitive price system which were present in the work of many economists from the earliest times. In particular this could be taken to represent the full formalization of the writings of Walras (1954).

The development of general equilibrium theory was a great step forward in the mathematization of a central concept of economic theory. It showed the delicacy of the many conditions needed to permit the functioning of an efficient price system. It also showed the power of new and elegant mathematical applications to the social sciences. But the development of a science calls for more than mathematics and logic. The relevance of and closeness of the abstractions to the functioning economy and the nature of the questions which can and cannot be answered by the theory developed must be considered with care.

1 [editorial note] R. Ruggles (1993), National Income Accounting: Concepts and Measurement. Economic Theory and Practice, Economic Notes by Monte dei Paschi di Siena, 22 (2), 1993, p. 235-264. 
General equilibrium theory is admirably suited to illustrate basic relationships in equilibrium but offers few if any insights into process. Time and uncertainty have essentially disappeared from this apotheosis of the price system. But it is time and uncertainty which are the concerns of everyday economic life and the problems of how to account for the influence of time and uncertainty in the ongoing economic process are central to the development of accounting.

Koopmans (1977) has noted general equilibrium theory is essentially preinstitutional in character. The ability to formulate and answer in a sophisticated way many deep problems about the relationship between prices and efficient production has been of great significance in laying the groundwork for an economics that accommodates process. But this strength should not serve to hide the gap between verbal descriptions of competition and the highly non-institutional and process-free description of preferences, ownership and technological relations that make up the basic elements of general equilibrium theory.

Many of the important developments in mathematical economics in the past twenty years have been directed towards finding mathematical generalizations which weaken assumptions on preferences, take care of boundary equilibria or cast light upon production conditions A certain amount of work has been done on the stability of equilibrium points under perturbations in excess supply and demand conditions; but few general results are known concerning the dynamic of socio-economic feedback mechanisms for the formation of price.

The next step in the development of microeconomics is in building full process models showing the formation of prices via the market or showing the manipulation of prices via a centralized economic planning agency. But any attempt to do this calls far the specification of updating mechanisms of the economy regardless of any equilibrium considerations and it is precisely the recognition of the need for the description of the updating implicit in economic process that has been central to the development of accounting. Any attempt to construct full process models, even at the highest level of abstraction forces the modeler to acknowledge the existence of, or to invent economic institutions, because they are the carriers of economic process and in one form or the other appear as necessary consequences of fully defining "the rules of the game". The accountant takes the institutions as a fact of life. A successful post-general equilibrium theory must have them as a logical necessity of process. The growth of specific institutions undoubtedly depends on a host of factors involving history, chance, culture and technology pertaining to each society.

Ideologies often use scholarly theories as part of the social process of legitimization. The elegance, level of abstraction and apparent generality of general equilibrium theory appears to provide an intellectual justification for the extreme proponents of laissez faire. The market will take care of everything. Free 
unconstrained competition without the interference of government or society has now been "proved to be the best of all possible worlds" by advanced mathematical methods. It would be a great blessing if this were true. Unfortunately the truth lies elsewhere. The careful economic theorist with no immediate political cause to legitimize can simultaneously see the great intellectual contribution of the theory and its limitations. An understanding of the limitations may help to bring it closer to reality and in doing so may also explain why many of the definitions of the microeconomist differ from the accountant and businessman concerned with the processes of every day production and trade.

The limitations of the general equilibrium model are as follows:

1. It is basically non-institutional.

2. It distinguishes too few differentiated economic agents.

3. Although equilibrium conditions are specified, no explanation of price formation is given. The general equilibrium model is static.

4. There is no essential role for money.

5. The agents are modeled non-strategically; prices are given, not formed.

6. The model is essentially timeless. Although one may make a simple pro forma change of notation which treats goods in different time periods as different goods, hence replaces an optimization problem in $M$ dimensions by one in $M T$ dimensions where $M$ is the number of goods and $T$ the number of the periods; this mathematical extension picks up only a few of the substantially new phenomena involved in the consideration of time and process in an economy.

7. The horizon is infinite and the agents appear without context at the start and disappear at the end.

8. The many problems posed by uncertainty in an actual economy are avoided by the same type of device that was used to extend the model to several periods. Suppose that an economy trades in $M$ commodities and that it can be in any one of $K$ states of nature. We may consider an economy with trade in $M K$ commodities which may be regarded as options.

9. The proofs of the existence of an efficient price system were independent of the number of competitors indicating that the mathematical model though appropriate for the study of efficient prices is not necessarily appropriate for the study of competitive price formation.

10. The general equilibrium model was not designed to study economies with an intermix of monopolistic, oligopolistic and competitive elements yet every economy has this mix.

11. It is an inadequate model for the study of non-symmetric information conditions, yet disclosure of costs and other competitive information are of critical importance to the economy. 
12. It has no satisfactory explanation of unemployment. In essence it offers an ideological opportunity to claim that there is no such thing as unemployment because in the best of all possible worlds without governmental or other institutional constraints the markets would adjust so that all who wished to work could find a job at the appropriate price.

13. Bankruptcy plays no role. There is neither birth nor deaths of firms. Yet a basic understanding in accounting is the need to differentiate ongoing enterprise evaluations from liquidation evaluations. Furthermore the elementary dynamics of economic process in a world with credit illustrates the proposition that the system may attain a state where prior commitments cannot be met. In such an instance bankruptcy laws become a logical necessity not merely an institutional fact.

14. Expectations are finessed. There is no learning.

The general equilibrium model does not need markets, banks or other credit or financial institutions, as trust is implicitly perfect. All trade is balanced at the end of the market and each individual at the start of trade has available implicitly a credit line equal to his net worth "at market", i. e. the worth of his initial assets at the final market price.

Firms are not institutions. Production is described by production correspondences available to all who have the resources. It is as though the only items necessary to bake a cake were the ingredients and a recipe (free to and immediately understood by all). The firm as an entity with an internal organization and a management with goals of its own is not included in this abstraction.

In the Debreu model there is really only one major actor - the consumer, and one shadow actor - the producer. The consumer has his own preference ordering and tries to maximize his own welfare. The producer is a shadowy manager of a firm which may be owned by stockholders other than himself. Even though his interests may conflict with others he is modeled as a profit maximizing perfect fiduciary who flows through the profits to a non-voting ${ }^{2}$ group of stockholders. The definition of profit depends upon the whole finite period being considered. There is no real concern with the accountant's need to define annual profit.

In macroeconomic models and in economic life we frequently distinguish investors, savers, speculators, brokers, bankers, consumers, manufactures,

2 [Shubik's note] It is hard to give much meaning to stockholder voting in the general equilibrium model without specifying a great amount of corporate law and running the risk of losing price system if the laws are not appropriate. 
retailers and others. It is important to ask at what level of abstraction do or should these distinctions appear.

The general equilibrium model is essentially static in the sense that time is handled by merely enlarging the number of variables and renormalizing (Wold, 1969). Work on sequences of economies (Green, 1973) and the infinite horizon have modified this. Even so in the work of Arrow and Debreu (1954) and Debreu (1959), no explicit mechanism for the formation of price is given, i. e. no formal markets exist. It is not surprising that at this level of theorizing one cannot distinguish a competitive economy with prices arising from competitive behavior from a socialist economy with controlled prices. The difference between them is in the mechanism of price formation; but in this theory the mechanism [is] left out.

In any complex economy, money plays a far more important and subtle role than merely acting as a unit of account. Yet there is no role for it in general equilibrium model. In the past few years there have been considerable efforts made by Hahn (1973), Starr (1974), Grandmont and Younes (1972), and many others, to introduce money into a modified general equilibrium model. Although considerable progress has been made this work is hampered by trying to stay too close to the original general equilibrium formulation.

The general equilibrium theory is nonstrategic. Prices appear by magic and the individual consumer is constrained to maximize his welfare given these prices. It is an assumption of the general equilibrium theory that the individual maximizes his welfare as though prices were given. Starting with a strategic view of competition such as illustrated by Cournot (1897) this is a deduction from the theory when the system is modeled as a game of strategy and solved for its noncooperative equilibria.

Points 6, 7 and 8: that the general equilibrium model is essentially timeless, avoids the problems with exogenous uncertainty and has economic agents who are all present at the start of the economy and disappear at the end, are all essentially, the artifacts of modeling the economic system.

The economic meaning to enlarging the number of different commodities traded in an economy with $M$ commodities, $J$ trading periods and $K$ states of nature, to $M K T$ is that perfect future markets and insurance contracts exist for all times and all circumstances. This is an assumption which implies perfect knowledge and trust and merits modifying.

Because the general equilibrium model is examined for the existence of an efficient price system that is independent of the number of traders, it does not offer a means far studying the effect of thin markets and few competitors. Such a distinction calls for showing how the presence of different numbers of competitors of different sizes and with different levels of control influences the 
formation of price. Both in law and accounting problems involving the valuation of assets in thin or inactive markets are of considerable importance. ${ }^{3}$

In summary the general equilibrium system provides considerable insight into the technological and preference requirements for a society to be in a position to use a price system to achieve efficient production and distribution. As it is not concerned with process no distinction is made between a centralized price system or one that comes about via competition among many small agents. Furthermore no insight is provided about the problems of control or the mechanisms required in either an enterprise or centralized economy. These limitations in no way detract from the contribution to the understanding of the role of price as an efficient decentralizing device. The general equilibrium system provides a natural basis or departure point from which to consider control mechanisms. It is in the control mechanisms for economies which may have a varying intermix of competitive or controlled prices that financial instruments and institutions play their role.

The gap between the language of the economist and the accountant comes about to a great extent because even the most sophisticated general economic models are too simple to be used to analyze in any depth the myriad of ad hoc problems which confront the businessman and accountant in everyday life. Accounting is designed as a practical applied information processing device to aid the businessman with limited time, knowledge and data processing capability to steer his enterprise in a world laden with uncertainty. Many of its basic concepts such as the valuation of assets, the definition of profits or the assignment of depreciation are derived from a necessary blend of techniques of aggregation and disaggregation of information, taking into account costs of obtaining the data, together with blending in consideration of law, custom of the society and practices of the business enterprises. Like his macroeconomic accountant counterpart the business accountant is immersed in process and in assisting in every day practice. The founder of business accounting was a mathematical theorist and currently the modern professors of accounting recognize the need for a science of accounting as part of the information sciences as well as a practice of accounting, deeply reflecting the details of economic process in economies with different legal systems and customs. The paper of Yuji Ijiri in this journal ${ }^{4}$ serves to illustrate that the levels of abstraction and concerns in the development of accounting theory are close to those in microeconomic theory.

3 [editorial note] as Pantaleoni (1904), Alcune osservazioni sulle attribuzioni di valori in assenza di formazione di prezzi di mercato [Some observations on the recognitions of values when price formation lacks], Giomale degli Economisti, March p. 203-231 and April p. 307-325, early recognised. 4 [editorial note] Y. Ijiri, The Beauty of Double-Entry Bookkeeping and its impact on the Nature of Accounting Information, Economic Notes by Monte dei Paschi di Siena, 22 (2), 1993, p. 265-285. 
The gap between modern accounting theory and practice and economic theory is large and to a great extent exists because the need to reconcile the two was less important in simpler economies. The reconciliation must come from both ends, like the digging of a major tunnel. In this note only the economists' responsibility is stressed.

Much of this note has been devoted to a critique of general equilibrium theory, yet paradoxically this is because of my belief as to how important and valuable it is to the task noted above. I suggest that general equilibrium theory produced a considerable insight into the nature of some of the basic features of the price system. The rigorous standards of logical consistency and completeness in the characterization of an extremely complex problem were obtained at the cost of considerable simplification. In particular all traces of economic process were eliminated from the basic structure studied. But the next step is to transform and extend the models of general equilibrium theory into process models. This can be done utilizing game theory following the work of Cournot (1897) to its more modern manifestations (Dubey \& Shubik, 1978; Shapley \& Shubik, 1977; Shubik, 1973). The strategic market game is a microeconomic process model of the economy. Both the modeling and the analysis force the construction of a mathematical institutional economics where apparently minor institutional detail such as bankruptcy and default rules or details concerning accrual accounting turn out to be logical necessities in being able to well define process. By insisting on process models which are well defined playable games the modeling emphasis is away from equilibrium and calls for the description of carriers of process which in turn can be interpreted as elementary market and financial institutions. In such a formulation virtually every concern of the practicing accountant and financial analyst, be it seniority of claims, definition of periodic profits, treatment of inventories, evaluation of "haircuts" for risky loans or treatment of strategic opportunities as off-balance sheet assets or liabilities appear as needed rules to facilitate process.

From a purely practical point of view the reconciliation between economic theory and both macro and micro accounting may come about to a great extent by the growth in sophistication of the economic agents who understand that there are great fortunes to be made in arbitrages between accounting and legal conventions which do not match the underlying economic realities sufficiently closely. Thus in the early development of commodity and stock markets the brokers could earn considerable incomes off the escrow accounts or delays in settlement of the balances of their clients, and to this day what constitutes a legal transaction in one jurisdiction may be interpreted otherwise in a different jurisdiction. Further examples are provided by an old New York observation that the wise businessman does not maximize wealth, but undisclosed wealth, and 
by noting that an accounting convention which treats an investment as an immediate expense may completely transform a tax bill.

Keynes (1936) observed many years ago that: "Practical men, who believe themselves to be quite exempt ham any intellectual influences, are usually the slaves of some defunct economist". It is undoubtedly true that the practicing businessman and accountant has little use for the economic theorist, but the theorist, if he wishes to live up to the praise of Keynes must understand the world as it is. He must be able to fit Generally Accepted Accounting Principles and their European and other equivalent codes into his theorizing. He must remember that the rules of thumb, approximations and customary activities of the business community are not merely irrelevant ephemera to the theorist, but their peculiarities and paradoxes must at least be shown to be special cases of a general theory capable of explanation by the theory. If this is not the case, then the theory not the reality is at fault.

Acknowledgment: Reprinted with permission from Y. Biondi, A. Canziani, Th. Kirat (2007) eds. The Firm as an Entity: Implications for Economics, Accounting and the Law, London and New York: Routledge, chapter 5, pp. 73-81. Originally published by Economic Notes by Monte dei Paschi di Siena, 22 (2), 1993, p. 226-234.

We mourn the loss of Martin Shubik (1926 - 2018), a gifted scholar and a dear friend. Through his remarkable ideas and insights, Shubik helped founding and shaping the CONVIVIUM with his guidance, advice, and inaugural contribution "Accounting and Economic Theory: Past, Present, and Future" (DOI: https://doi.org/10.2202/2152-2820.1012). At the time of his passing on August 22, 2018, editorial work on this symposium on his last book with Eric Smith, The Guidance of an Enterprise Economy, has been underway. It is now published to honour him and his outstanding contributions to economics, management science, game theory, and accounting scholarship.

\section{References}

Arrow, K. J., \& Debreu, G. (1954). Existence of an equilibrium for a competitive economy. Econometrica, 22, 265-290. doi:10.2307/1907353.

Cournot, A. A. (1897). Researches into the mathematical principles of the theory of wealth. New York: Macmillan, (Bacon Translation of original 1838 French).

Debreu, G. (1959). The theory of value. New York: Wiley.

Dubey, P., \& Shubik, M. (1978). The noncooperative equilibria of a closed trading economy with market supply and bidding strategies. Journal of Economic Theory, 17(1), 1-20.

Grandmont, L. M., \& Younes, Y. (1972). On the role of money and the existence of a monetary equilibrium. Review of Economic Studies, 39(3), 355-372. doi:10.2307/2296364. 
Green, L. R. (1973). Temporary general equilibrium in a sequential trading model with spot and futures transactions. Econometrica, 41(6), 1103-1123. doi:10.2307/1914039.

Hahn, F. (1973). On the foundations of monetary theory. In M. Parkin, \& A. R. Nowbay (Eds.), Essays in modem economics. New York: Harper and Row.

Keynes, J. M. (1936). The general theory of employment, interest and money. London: Macmillan.

Koopmans, T. C. (1977). Concepts of optimality and their uses. The American Economic Review, 67(3), 261-274.

Pacioli, L. (1494). Summa de arithmetica, geometria, proportioni et proportionalita.

Shapley, L. S., \& Shubik, M. (1977). Trade using one commodity as a means of payment. Journal of Political Economy, 85(5), 937-968.

Shubik, M. (1973). Commodity money, oligopoly, credit and bankruptcy in a general equilibrium model. Western Economic Journal, Il(l), 24-38. doi:10.1111/j.1465-7295.1973.tb00959.x.

Starr, R. (1974). The price of money in a pure exchange economy with taxation. Econometrica, 42, 45-54. doi:10.2307/1913684.

Studenski, P. (1958). The income of nations. New York: New York University Press.

Walras, L. (1954). Elements of pure economics (tr. W. Jaffe), Homewood, IL: RD Irwin, original 1874, 1877, Élements d'économie politique pure, L. Corbaz, Lausanne.

Wold, H. O. (1969). Mergers of economics and philosophy of science. Synthese, 2, 427-482. doi:10.1007/BF00869929. 